\title{
RANCANG BANGUN SISTEM INFORMASI PENJUALAN DI SHOP BERBASIS WEB
}

\author{
Adhiyat Suhendar ${ }^{1}$, Ahsani Takwim², Alma Maulani Farkah ${ }^{3}$, Pandu Gumilar ${ }^{4}$, Vina Martina Dalih ${ }^{5}$ \\ Program Studi Teknik Informatika ${ }^{1,2}$, Program Studi Manajemen Keuangan Syariah ${ }^{3,4,5}$ \\ Sekolah Tinggi Teknologi Bandung ${ }^{1,2}$, UIN Sunan Gunung Djati Bandung ${ }^{3,4,5}$ \\ adhiyat22@gmail.com¹, ahsanitakwim@sttbandung.ac.id², almamaulanif@gmail.com³, gumilarpandu29@gmail.com \\ martinadalih@gmail.com ${ }^{5}$
}

\begin{abstract}
Abstrak
Fashion menjadi bagian yang tidak dapat dilepaskan dari penampilan dan gaya keseharian. Benda-benda seperti pakaian, aksesoris dan style yang dikenakan bukanlah sekedar penutup tubuh dan hiasan, melainkan sebagai bentuk alat komunikasi non verbal dalam menyampaikan identitas pribadi atau identitas kelompok. Perkembangan dunia fashion yang berkiprah di Indonesia itu sendiri dapat dikatakan mengalami peningkatan di beberapa dekade terakhir. Hal ini di dukung oleh berbagai sisi, baik dari sisi designer lokal yang kini semakin potensial, tingkat perekonomian yang membaik, sampai sektor ritel yang ikut serta mengalami perkembangan pesat. Sejarahnya dimulai dari Abad 700-1000 SM, Abad ke-15 atau ke-16 masehi, abad ke-17, abad ke-18, abad ke-19 . Perkembangan trend fashion di indonesia sangat dipengaruhi oleh budaya Eropa dan Asia terutama Busana Korea belakangan ini. Fashion di Indonesia telah berkembang dengan baik dalam sejarah. Dalam proses perancangan busana sendiri diawali dengan membuat konsep, melakukan observasi dan eksperimen untuk menentukan target market pakaian Di shop yang dibuat. Data primer yang diperoleh berupa hasil pengalaman, observasi, dan eksperimen. Data sekunder adalah studi kepustakaan yang membantu proses desain dan produksi. Setelah menghimpun data yang diperlukan, kemudian proses yang di lakukan adalah ekseperimen reka bahan seperti teknik sablon puff, quilting dan tucking. Proses dilanjutkan dengan realisasi dari pakaian yaitu tahap pembuatan pola dan finalisasi koleksi. Desain busana Di shop yang dibuat memiliki siluet geometris namun tetap ergonomis, sehingga nyaman digunakan oleh masyarakat perkotaan. Target konsumen yang ingin dicapai adalah wanita dewasa muda dengan rentang usia 21-30 tahun. Tujuan yang ingin diperoleh adalah memenuhi kebutuhan sandang yang tidak hanya indah dipakai, namun menekankan juga pada fungsional pakaian. Pakaian yang dipakai oleh masyarakat dengan gaya hidup aktif, khususnya wanita dibuat dengan memperhatikan fungsi kenyamanan dan keamanan.

Kata kunci : Fashion, Website, Teknologi.
\end{abstract}

\begin{abstract}
Fashion is an inseparable part of daily appearance and style. Objects such as clothes, accessories and styles that are usually used as body coverings and decorations, but as a form of non-verbal communication tool in adding personal identity or group identity. The development of the fashion world that takes part in Indonesia itself can be said to have increased in the last few decades. This is supported by various aspects, both from local designers who are now increasingly potential, the level of the economy is improving, to the retail sector which participates is experiencing rapid development. Its history starts from 700-1000 SM, 15th or 16th masehi, 17th century, 18th century, 19th century. The development of fashion trends in Indonesia is strongly influenced by European and Asian culture, especially Korean clothing lately. Fashion in Indonesia has developed well in history. In the fashion design process itself, it begins with making a concept, conducting observations and experiments to determine the target market for clothing in the store that is made. Primary data obtained in the form of experiences, observations, and experiments. Secondary data is a literature study that helps the design and production process. After collecting the required data, then the process carried out was experimental design of materials such as puff screen printing, quilting and tucking techniques. The process continues with the realization of the clothes, namely the stage of making patterns and finalizing the collection. The fashion design in the shop is made to have a geometric silhouette but is still ergonomic, so it is comfortable to use by urban people. The target consumers to be achieved are young adult women with an age range of 21-30 years. The goal to be achieved is to meet the needs of clothing that is not only beautiful to wear, but also functional clothing. The clothes worn by people with active lifestyles, especially women, are made with attention to the functions of comfort and safety. Keywords : Fashion, Website, Technology.
\end{abstract}

\section{PENDAHULUAN}

Fashion merupakan salah satu hal penting yang tidak dapat dilepaskan dari penampilan dan gaya keseharian. Bendabenda seperti baju dan aksesoris yang dikenakan bukanlah sekadar penutup tubuh dan hiasan, lebih dari itu juga menjadi sebuah alat komunikasi untuk menyampaikan identitas pribadi. Fashion tidak hanya menyangkut soal busana dan aksesoris semacam perhiasan seperti kalung dan gelang, akan tetapi benda-benda fungsional lain yang dipadukan dengan unsur-unsur desain yang canggih dan unik menjadi alat yang dapat menunjukkan dan mendongkrak penampilan si pemakai sehingga membentuk nilai-nilai yang ingin dikomunikasikan dari apa yang ditampilkan.

Fashion adalah suatu bentuk dari komunikasi, karna fashion dapat merepresentasikan apa yang seseorang lakukan melalui sebuah konteks layaknya kata-kata tertulis maupun lisan. Fashion atau pakaian pada dasarnya adalah berfungsi sebagai penutup, pelindung, kesopanan dan daya tarik namun tidak menutup kemunkinan peran fashion adalah untuk sebagai identitas diri baik individual maupun kelompok. Selain itu Fashion merupakan sebuah bentuk dari ekspresi individualistik dan digunakan individu untuk membedakan dirinya sendiri dan menyatakan beberapa keunikan. Fashion mendefinisikan pesan sosial yang dimiliki seseorang karna 2 pakaian yang berbeda yang dikenakan oleh orang yang berbeda memungkinkan adanya interaksi sosial yang berbeda pula. Berbagai tipe dari gaya fashion yang akan dibahas 
dapat mengungkapkan tema penampilan kita pada umumnya. Secara general, style fashion sendiri bertumpu pada karakter seseorang atau juga teman khusus dari cara berpakaiannya, berikut ini tipe gaya fashion.

Sejak 700-1000 SM, tekstil dan kain telah didokumentasikan sebagai salah satu produk penting yang dipertukarkan atau diperdagangkan antara bangsa-bangsa dan kerajaan di Asia Tenggara. Sebagai contoh, Kerajaan Sriwijaya (Palembang) memperdagangkan sumber daya alamnya untuk untuk ditukar dengan sutra dan gerabah dari Cina, dan dengan India, mereka menukarkannya untuk kapas. Tahunnya trend fashion selalu berubah-ubah, hal ini disebabkan karena kebanyakan orang tidak ingin memakai baju/pakaian yang modelnya sama setiap tahunnya. Perubahan trend fashion mulai baju yang di pakai sehari-hari sampai busana muslim pun kini telah mengalami perkembangan fashion yang cukup pesat. Berbagai model yang unik dan glamor banyak terlihat di pakai oleh kalangan artis dan publik figur yang selalu ingin menjadi trendsetter.

\section{TINJAUAN PUSTAKA}

\section{Sistem}

Sistem adalah suatu jaringan kerja dari prosedur - prosedur yang saling berhubungan, berkumpul Bersama - sama untuk melakukan suatu kegiatan atau untuk menyelesaikan suatu sasaran yang tertentu. Menurut Jerry Futzgerald, system adalah suatu jaringan kerja dari prosedur prosedur yang saling berhubungan, berkumpul bersama - sama untuk melakukan suatu kegiatan atau menyelesaikan suatu sasaran tertentu[1]. Sedangkan menurut Lani Sidharta, system adalah himpunan dari bagian - bagian yang saling berhubungan yang secara Bersama mencapai tujuan tujuan yang sama[2].

Berdasarkan pengertian sistem dari beberapa ahli di atas dapat disimpulkan bahwa sistem adalah suatu jaringan kerja dari prosedur prosedur yang saling berhubungan.

\section{Informasi}

Informasi merupakan sekumpulan data atau fakta yang telah diproses dan dikelola sedemikian rupa sehingga menjadi sesuatu yang mudah dimengerti dan bermanfaat bagi penerimanya. Pendapat Anton M. Meliono, informasi ialah data yang telah diproses untuk suatu tujuan tertentu. Tujuan tersebut iyalah untuk menghasilkan sebuah keputusan[3].

\section{Website}

Abdullah mengemukakan bahwa website adalah kumpulan-kumpulan halaman yang terdiri dari beberapa laman yang di dalamnya berisi informasi dalam bentuk data digital baik itu berupa gambar, video, audio, teks dan animasi lainnya yang disediakan melalui jalur koneksi internet[4].

\section{Fashion}

Pengertian yang sama juga dikatakan oleh Lypovettsky, Fashion merupakan bentuk perubahan yang bercirikan oleh rintikan waktu yang cepat, sehingga fashion merupakan kekuatan dari individualitas dengan mengizinkan seseorang untuk mengekspresikan dirinya dalam berbusana. Ilmuan lain juga ada yang mengatakan yaitu Polhemus dan Procter bahwa fashion digunakan sebagai sinonim atau persamaan dari istilah dandanan, busana dan gaya di dalam masyarakat[5].

\section{Metode Technology Acceptance Model (TAM)}

Menurut Davis 1989 metode technology acceptance model merupakan suatu model penerimaan system teknologi informasi yang digunakan oleh pemakai. Metode technology acceptance model digunakan untuk memberikan kemudahan bagi perusahaan maupun customer dengan memanfaatkan teknologi informasi[6].

\section{Unified Modeling Language (UML)}

Unified Modeling Language adalah bahasa spesifikasi standar yang dipergunakan untuk mendokumentasikan, menspesifikasikan dan membanngun perangkat lunak. UML merupakan metodologi dalam mengembangkan sistem berorientasi objek dan juga merupakan alat untuk mendukung pengembangan system [7].

\section{Model View Controller ( MVC)}

Menurut Daqiqil (2011:5) MVC adalah singkatan dari Model View Controller. MVC sebenarnya adalah sebuah pattern/teknik pemograman yang memisahkan bisnis logic (alur pikir), data logic (penyimpanan data) dan presentation logic (antarmuka aplikasi) atau secara sederhana adalah memisahkan antara desain, data dan proses"[8]. 


\title{
III. ANALISIS DAN PERANCANGAN
}

\author{
1. Data Umum Perusahaan
}

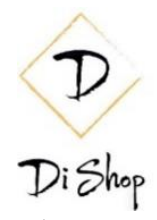

Gambar 1. Logo Di Shop

Di Shop didirikan tahun 2021, beralamat di daerah Bekasi Jawa Barat. Salah satu perusahaan di bidang fashion. Visinya menjadikan Di Shop sebagai sarana belanja online yang menyediakan fashion dari mulai atasan sampai bawahan dengan kualitas terbaik. Serta Misinya adalah :

a. Memberi pelayanan yang baik terhadap pelanggan

b. Menyediakan diskon untuk reseller dan langganan

c. Memilih bahan terbaik untuk dijadikan pakaian

d. Mempublikasikan dishop kepada seluruh kalangan masyarakat

Makna Logo

a. Bentuk; penulis memilih bentuk belah ketupat yang di dalam nya tedapat huruf D, Maksud dari bentuk belah ketupat ini ialah keseimbangan, karena setiap sisinya sama panjang dan mencakup 4 sisi dari arah yang berbeda. Bahwa dalam kehidupan harus ada keseimbangan dalam menjalaninya, porsi bekerja harus seimbang dengan porsi ibadah,usaha harus diimbangi dengan doa begitu juga dalam meraih kesuksesan.

b. Warna; Penulis memilih warna kuning dan hitam, kuning sendiri merupakan warna yang membawa kesan kebahagiaan,keceriaan dan optimis.Dimana pelanggan yang membeli produk di Di shop akan mempunyai rasa bahagia tersendiri jika ber belanja di toko kami Penggunaan warna kuning juga mudah menarik perhatian karena menyolok dibandingkan warna primer lainya, dan sering di pergunakan oleh perusahaan yang berjiwa muda dan kretivitas. Sedangkan warna hitam pada logo tersebut membawa kesan elegan, klasik, kekuatan serta ketegasan

2. Metode Penelitian

Penulis dalam membuat penelitian ini menggunakan metodologi penelitian kuantitatif dengan metode pengembangan perangkat lunak Technology Acceptance Model (TAM). Tahapan dalam TAM yang penulis gunakan dalam bab ini yaitu, Perencanaan dan desain. sedangkan untuk tahap pembuatan aplikasi dan pengujian ada di bab selanjutnya. Dalam melakukan metode pengumpulan data, penulis menggunakan metode wawancara sebgai bahan acuan. Kemudian peneliti mendapatkan berbagai informasi berdasarkan hasil wawancara. Dalam merancang dan membangun sistem peneliti menggunakan sistem informasi berbasis website.

3. Perencanaan

Berikut merupakan perencanaan dalam pengaplikasian system Di shop.

a. Flowchart Admin

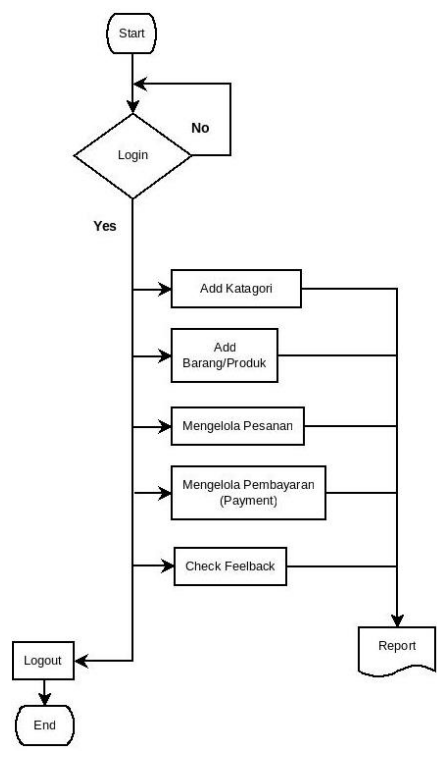

Gambar 2. Flowchart Admin 
b. Flowchart Customer

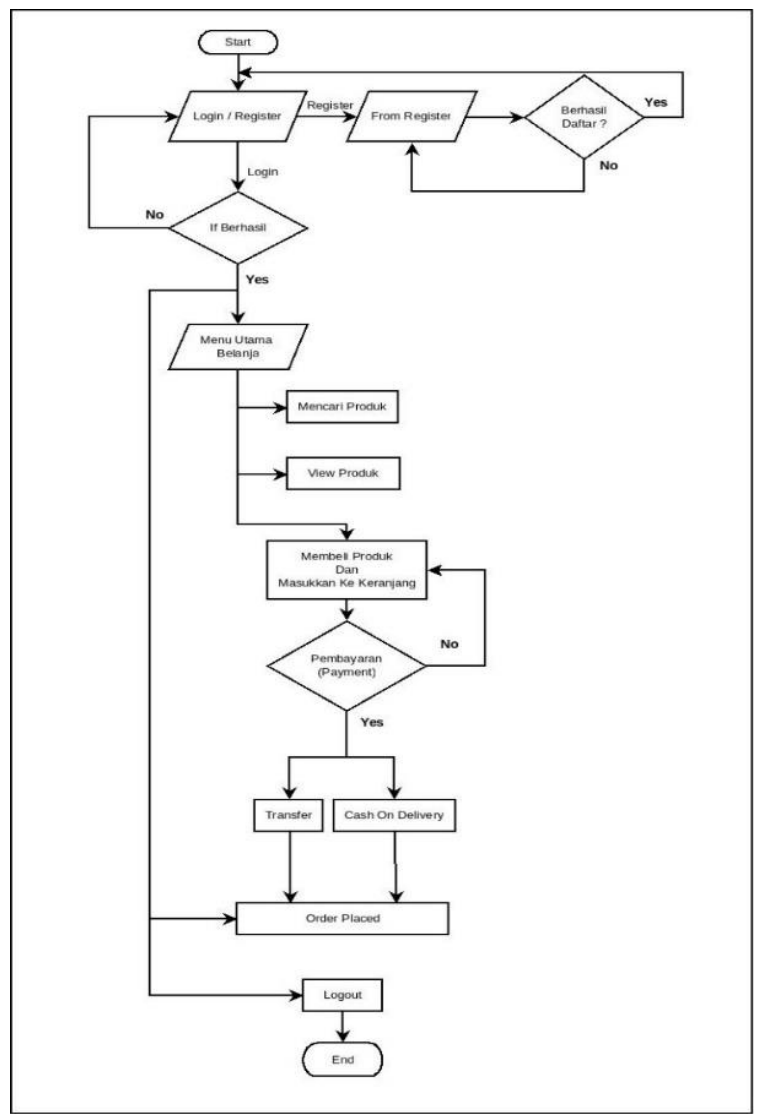

Gambar 3. Flowchart Customer

4. Gambaran Umum Sistem

Berikut Use Case Diagram dan Class Diagram pada Di shop.

a. Use Case Diagram

Berikut merupakan gambar use case diagram.

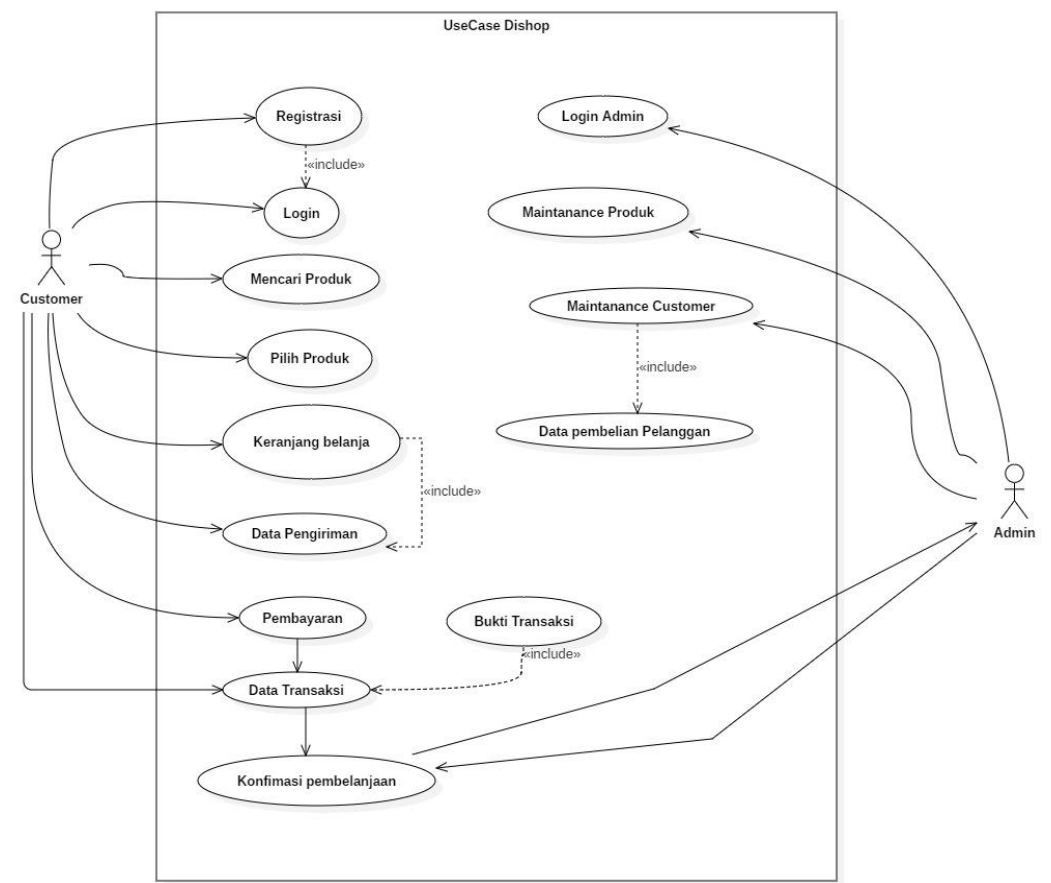

Gambar 4. Use Case Diagram 


\section{IMPLEMENTASI}

1. Implementasi Sistem

Berikut tampilan implementasi sistem sistem pada Di shop.

a. Halaman pengisian informasi login

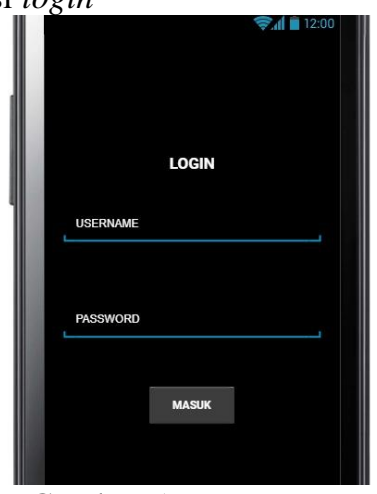

b. Halaman pemilihan produk

Gambar 5. Form Login

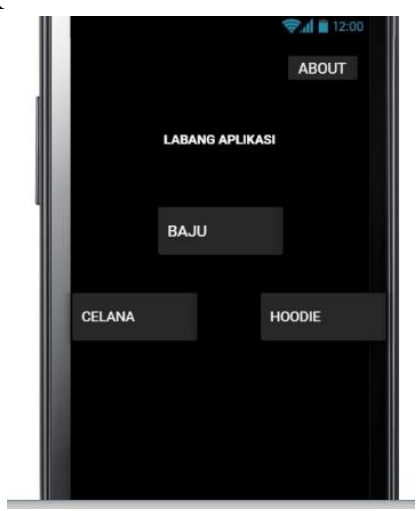

Gambar 6. Form Menu baju dan celana
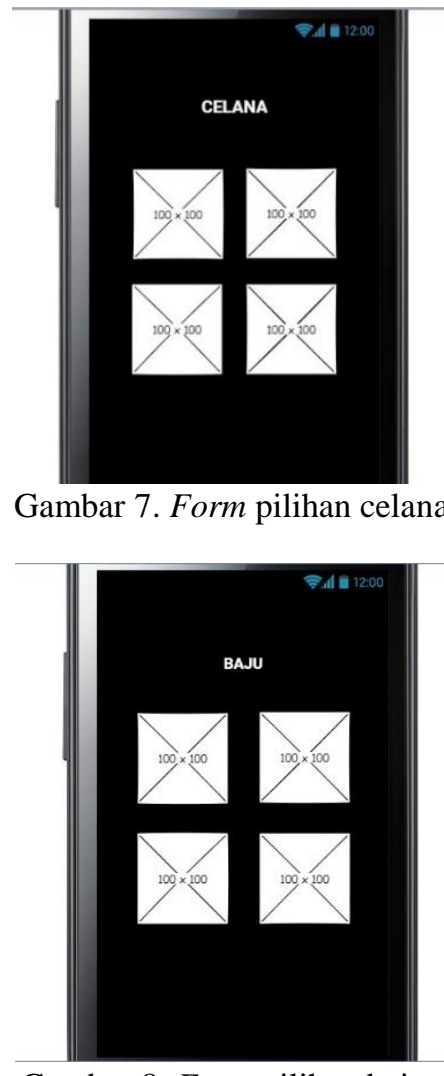

Gambar 8. Form pilihan baju 


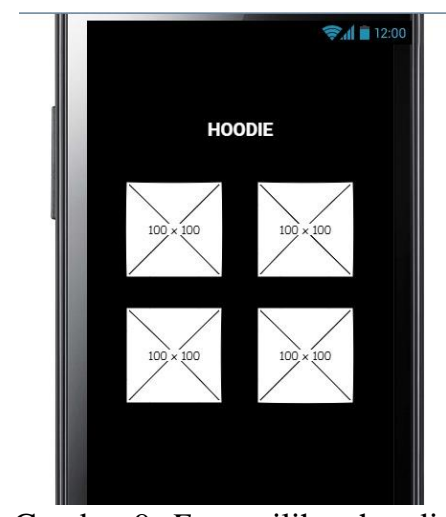

Gambar 9. Form pilihan hoodie

c. Halaman pengisian ulang

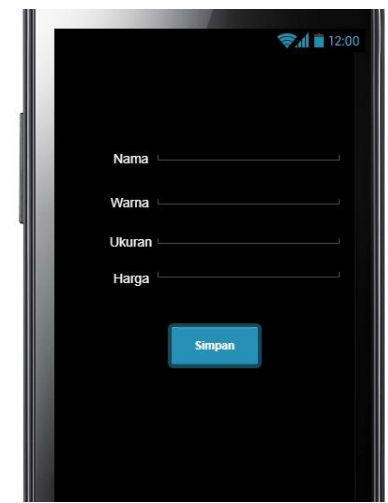

Gambar 10. Form pengisian ulang

d. Halaman nama kelompok

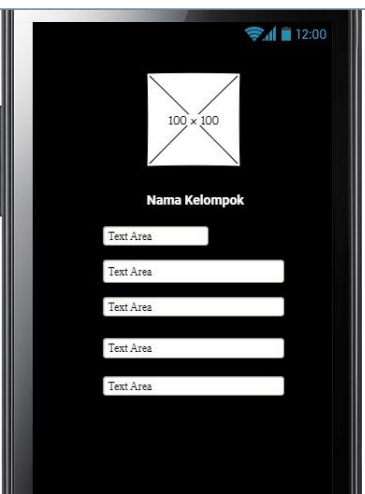

Gambar 11. Form nama kelompok

e. Halaman logo dan slogan

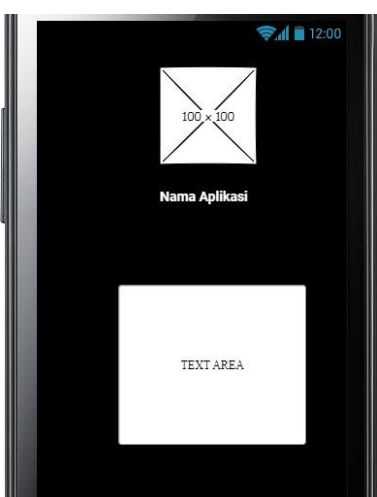

Gambar 12. Form logo dan slogan 
f. Halaman penutup aplikasi

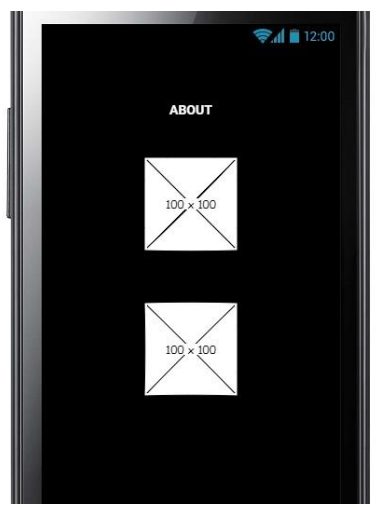

Gambar 13. Form about/tentang aplikasi

\section{KESIMPULAN}

Berdasarkan hasil dari implementasi dari penelitian yang berjudul "Rancang Bangun Sistem Informasi Penjualan online Di Shop" maka dapat ditarik kesimpulan sebagai berikut:

1. Sistem penjualan online shop ini dapat mempermudah semua orang yang ingin berlanja tanpa harus keluar rumah dan antri.

2. Dengan adanya online shop ini bisa menambah perekonomian owner dan bisa juga sebagai kerja sampingan selain pekerjaan utama,karena untuk membuka usaha seperti ini tidak harus selalu orang yang berpendidikan jadi bisa dilakukan oleh siapapun.

3. Membantu sebagai bahan peluang bagi orang yang ingin bekerja dibidang usaha.

4. Sistem informasi ini juga dapat memenuhi kebutuhan pelanggan yang sedang mencari pakaian.

\section{REFERENSI}

[1] Fitzgerald, Jerry. FitzGerald, Ardra F. and Stalling Jr, Warren D. (1981) Fundamentals Of System Analysis, Edisi kedua, John Willey \& Sons, New York.

[2] Lani Sidharta. (1995). Pengantar Sistem Informasi Bisnis. Jakarta: PT. Elex Media Komputindo

[3] Anton, Moeliono. (1990). Kamus Besar Bahasa Indonesia. Jakarta: Balai Pustaka

[4] Abdullah. Rohi. Web programing is easy, jakarta : elek media Komputindo.

[5] Malcoln Barnard, Fashion Sebagai Komunikasi Cara Mengkomunikasikan Identitas Sosial,Seksual, Kelas dan Gender, (Yogyakarta: Jalasutra, 2016), 13

[6] Davis, F. Davis. 1986. A Technology Acceptance Model for Empirically Testing Nea End-User Infortion Systems : Theory and Results, Doctoral Disertation, MIT Sloan School of Management, Cambridge, MA.

[7] Gata, Windu dan Gata, Grace. (2013). Sukses Membangun Aplikasi Penjualan dengan Java. Jakarta : Elex Media Komputindo.

[8] Daqiqil, Ibnu. 2011. Framework CodeIgniter: Sebuah Panduan dan Best Practice, Pekanbaru. http://www.koder.web.id/Frameworkcodeignitersebuah-panduan-dan-best-practice 30 April 2012 